\title{
The Determination of Faculty Members' Perceptions and Knowledge of the Teacher-Scholar Model at a Primarily Teaching Institution
}

\author{
Louis S. Nadelson (Corresponding author) \\ University of Central Arkansas, Conway AR, 72035, USA \\ Tel: 1-501-450-3254_E-mail: Inadelson1@uca.edu \\ Carlos Baldo* \\ Colorado Mesa University, Grand Junction CO, USA \\ Nancy Banman* \\ Colorado Mesa University, Grand Junction CO, USA
}

Ed Bonan-Hamada*

Colorado Mesa University, Grand Junction CO, USA

Robin Calland*

Colorado Mesa University, Grand Junction CO, USA

Carmine R. Grieco

University of Central Arkansas, Conway AR, USA

Colorado Mesa University, Grand Junction CO, USA

Christine Noel*

Colorado Mesa University, Grand Junction CO, USA 


\title{
Suzanne Owens*
}

Colorado Mesa University, Grand Junction CO, USA

\author{
Kristin Santos* \\ Colorado Mesa University, Grand Junction CO, USA
}

\author{
Elizabeth Sharp* \\ Colorado Mesa University, Grand Junction CO, USA \\ * Authors all contributed equally and are listed alphabetically
}

Received: November 15, 2018 Accepted: January 4, 2019 Published: February 6, 2019

doi: 10.5296/ire.v7i1.13921 URL: https://doi.org/10.5296/ire.v7i1.13921

\begin{abstract}
The teacher-scholar model was created in recognition of the expectations that university faculty members will engage in both high-quality teaching and scholarship. The adoption of the teacher-scholar model at universities has been mixed. Our exploratory case study investigation took place at a primarily teaching university in which the model was recently embraced. We wanted to know about the extent of the faculty members' knowledge, perceptions, preparation, and engagement in the teacher-scholar model. Our results indicated that the faculty members held constrained levels of knowledge of the model, neutral perceptions of model, a range of levels of preparation to productively engage in the model, and took an array of approaches for model engagement. We also found that the more the faculty members have engaged in scholarship and had been in higher education longer were more likely to hold positive perceptions of the model and had higher levels of knowledge of the teacher-scholar model. Our findings suggest that there is a need for long-term focused professional development focused on the teacher-scholar model at universities where the model is being adopted.
\end{abstract}

Keywords: Boyer Model, promotion, scholarship, teacher-scholar model, tenure

\section{Introduction}

Faculty members at universities are commonly expected to divide their workload between scholarship, teaching, and service. Depending on the composition of the university, the percent of time that faculty members devote to each of these three activities may contrast sharply. For example, at institutions in which research is the highest priority, the focus on scholarship is likely to overshadow teaching, which is in stark contrast to a primarily 
undergraduate institution (PUI) where it is common for faculty members to prioritize teaching over research. Regardless of the institutional configuration, many' stakeholders agree that universities and students benefit when faculty members distribute their time between the activities of teaching and scholarship (e.g. Brew, 2003; Jencks \& Reisman, 1968). Dedication to all of these facets is necessary to achieve the mission of universities to educate, explore, and provide support to the academic community.

Typically, both teaching-intensive and research-intensive institutions are imbalanced in their attention to the three primary facets of the university mission. The faculty members at universities focused on research or scholarship are typically hired because they are active and successful scholars. The expectation for research focused faculty members is that they be highly productive and widely recognized scholars and adequate at teaching. Thus, to meet all aspects of the university mission at research focused universities typically requires the faculty members to be effortful in shifting some of their attention from scholarship to focus more on teaching and student learning. The situation is reversed at PUIs where faculty members are typically hired because they demonstrate they are skillful and committed teachers and adequate scholars. At PUIs, the expectations of expertise in and dedication to scholarship are commonly secondary to the demand for teaching experience. Therefore, leadership at PUIs may need to invest in efforts to encourage their faculty members to be more engaged and productive in scholarship. In efforts to enhance the teaching proficiency of faculty members at high research institutions, scholars have created models intended to foster higher levels of successful teaching (e.g. Kenny et. al, 2001; Kuh, Kinzie, Schuh, \& Whitt, 2005). Similarly, models have been created to enhance the scholarly activities of faculty members at PUIs such as the teacher-scholar model (Boyer, 1990).

The push to increase scholarship through the adoption of the teacher-scholar model at PUIs led us to wonder about faculty members' perceptions, knowledge, and engagement of and in the teacher-scholar model at a primarily teaching institutions. Given the need for empirical evidence related to adoption of the teacher-scholar model and the dearth of published work in the area we determined there was justification for an exploratory investigation of a single institution as a case study. The institution we selected for our case study was a PUI that had recently institutionalized the teacher-scholar model as a way to meet the increased expectations for faculty member engagement in scholarship. We predicted that as the institution matures and transitions to greater emphasis on scholarship, the perceptions, knowledge, and engagement of faculty members would remain focused on teaching and therefore, there would be an imbalance in their scholarship resulting in a misaligned with expectations with the teacher-scholar model.

\section{Review of Literature}

\subsection{What is the Teacher-Scholar Model?}

The teacher-scholar model was formally detailed by Boyer (1990) in a Carnegie Foundation report in which he described the four facets of academic scholarship: discovery, integration, application, and teaching. In an update to the report, Boyer (2004) maintains, "Almost all colleges pay lip service to the trilogy of teaching, research, and service, but when it comes to 
making judgments about professional performance, the three rarely are assigned equal merit. Today, when we speak of being 'scholarly,' it usually means having academic rank in a college or university and being engaged in research and publication" (p. 571). Thus, being a scholar has morphed into the perception that research is a priority and is the essential work of academic professionals - an understanding which Boyer (2004) argues deviates from prior conceptions of scholarship.

Boyer (1990) developed the teacher-scholar model out of a desire to communicate scholarship as more than discovery research. The model addresses the potential tension between teaching and research by suggesting the existence of a potential bridge between the two efforts of faculty members. Thus, Boyer (2004) proposed that scholarship could be conceived as being one of four separate, yet overlapping forms: the scholarship of discovery, integration, application, and teaching. Discovery scholarship amounts to what most academics associate with traditional investigative experimental research, in which the gathering of empirical data adds to and advances knowledge within a discipline. Integration scholarship is defined by inter-disciplinary engagement in activities that lead to the creation of novel intellectual connections that cross disciplines, resulting in new insight and potentially greater context to academic work. Application scholarship is defined by the translation of discovery results to practice or policy resulting in benefits to citizens, communities, or society. Teaching scholarship involves empirically documenting the outcomes of curricular and instructional choices on student learning. Common to the four forms of scholarship is the gathering of empirical data and sharing the outcome with the greater community. As McKenna, Bickle and Carroll (2002) contend, for work to be considered scholarship, faculty members must share their work through publication, presentation, or exhibition.

The teacher-scholar model is intended to provide support for the notion that faculty members can strive for excellence in both domains and potentially engage in activities that bridge the efforts. As Ruscio (2013) argues, "The dash between teacher and scholar is meant to be a link, not a line of demarcation" (pp. 27). The teacher-scholar model provides support for activities such as faculty members collaborating with their students in research, which involves both teaching (through mentoring) and scholarship (through research).

Some may perceive that the Boyer model implies that peer reviewed publications are the only acceptable product that can be considered as evidence of scholarship. However, as McKenna et al., (2002) share, when discussing the teacher-scholar model, there is firequently a need to clarify that the teaching part of the model refers to using teaching as a context for scholarship which includes sharing the outcome of the associated scholarship with a broader audience comprised of professional peers. The process of sharing the outcomes of scholarly activities could take place through a number of products or processes including peer reviewed articles, invited articles, conference proceedings, and presentations at professional conferences (Gardner, McGowan, \& Moeller, 2010). Regardless of the form of sharing, the output, product, or sharing of results is a necessary component of the teacher-scholar model cycle.

The perception that teaching and research are distinct activities has a long history. For 
example in 1908, Henry S. Pritchett stated, "Research is a word to conjure with, but in the last two decades more sins have been committed in its name against good teaching than we are likely to atone for in the next generation" (as cited in Ziolkowski, 1996). The teacher-scholar model resolves the often perceived dichotomy between research and teaching that has been present in higher education for many years. University faculties, and particularly tenure and promotion committee members, continue to consider teaching and scholarship as distinct academic activities. Jencks and Riesman (1968) suggest that university faculty members are more motivated to share their knowledge to inform their colleagues and less motivated to share their knowledge with students through teaching. Resolving the conflict, the teacher-scholar model blends the two activities, with the expectation that scholarship enhances teaching. The assumption is that embracing the teacher-scholar model, and thereby blending the two activities, provides motivation for faculty members to engage in scholarship that leads to better teaching and improves student learning (Gardner et al., 2010).

Faculty and administration at many primarily teaching institutions have adopted the teacher-scholar model to increase the scholarship of faculty members and, similarly, institutions with a primary emphasis on scholarship have adopted the model to increase the quality of the teaching (Toth \& Sullivan, 2016). The variety of institutions that can potentially enjoy the benefits of the teacher-scholar model serves as a robust justification for assessing faculty members' perceptions, knowledge, and engagement associated with the teacher-scholar model.

\subsection{The Teacher Scholar Model from an Institutional Perspective}

While there are potential benefits to the faculty members at post-secondary institutions for the adoption of the teacher-scholar model, the adoption of the model may also benefit the institution as well. Jencks and Riesman (1968) argued that without research faculty members cease to develop intellectually in ways that lead to stagnation in knowledge, which influences their teaching. Thus, by engaging in scholarship faculty members can enhance their teaching effectiveness which can lead to greater student satisfaction with the institution, and increasing scholarly productivity which can bring recognition to the institution as a place where innovation and exploration are part of the culture. The combination of positive student satisfaction and scholarly contributions impact the reputation and value of institutions as places of learning and new knowledge formation.

We maintain that perceptions of the value of institutions to society are associated with levels of public funding for public institutions. Given the nearly predictable ongoing decline in government funding for public education in the United States (Fabricant \& Brier, 2016), post-secondary institutions arguably have a reputation issue associated with perceptions of the value of an education. As a result, schools have had to market themselves more aggressively to compete with other schools for tuition dollars to cover operating costs.

To complicate matters further, efforts to regulate post-secondary institutions to ensure that students graduating from the institutions attained the requisite skills to secure a job that paid a wage commensurate to the investment in their education. The result of the desire to regulate these programs was policies that considered the ratio of student debt incurred to earn a degree, 
to post-graduation earning potential. Schools with a high debt to the predicted salary ratio for graduates could be subjected to sanctions imposed by the U.S. Department of Education (2015).

The two issues of a post-secondary school experiencing shifts in reputation due to faculty productivity and the potential for reduction in standing based on student earing potential have resulted in institutionalized assessment, including evaluation of faculty scholarly productivity. Since scholarship and teaching are fundamental activities expected of faculty members, greater expectations have been placed upon documenting these facets of faculty performance and responsibilities to support claims of institutional value. For example, faculty that began teaching in the late 1990s at some PUIs were not expected to engage in scholarship to successfully be promoted and granted tenure. However, due to external pressures, the expectations for promotion and/or tenure have shifted to now requiring scholarship, including scholarly publications and evidence of ongoing research. Because the teacher-scholar model is well aligned with the changing expectations of faculty members, there is warrant for examining the preparation, perceptions and engagement in scholarship by faculty members working at PUIs.

\subsection{Implementation of the Teacher-Scholar Model}

University faculty members and administration have taken a variety of approaches to the adoption of the teacher-scholar model. At some universities the faculty and administration have taken steps to modify their tenure requirements and faculty member evaluations to align with the teacher-scholar model (Cruz, Ellern, Ford, Moss, \& White, 2009; Gardner et al, 2010; Schweitzer, 2000). At other universities, the adoption of the model has been embraced by the faculty and administration as a mechanism for changing the culture and definition of what can be considered as scholarship (Witt, Harris, Yarhouse, Sawyer, \& Behnke, 2007). We maintain that there is possibly a third group of universities in which the faculty and administration have embraced the idea of the teacher-scholar model in theory, but have not taken action to make substantive changes to their procedures and policies to align with the model.

As the teacher-scholar model has gained more acceptance in higher education, some universities have used the definitions of the works of Boyer (1990) in an attempt to delineate teaching and scholarship (Ruscio, 2013). When there is institutional support of the teacher-scholar model there is commonly evidence of an amalgamation of teaching and scholar activity, resulting in greater scholarly productivity (Schweitzer, 2000; Tobin, Bordonaro, \& Schmidt, 2010). For example, within the discipline of counseling, there is evidence of the Boyer model of scholarship represented in the articles published in professional journals (Schweitzer, 2000; Tobin, Bordonaro, \& Schmidt, 2010).

At some universities the faculty and administration attempt to classify scholarship into the four forms proposed by Boyer discussed. In these cases, there may be endeavors at the universities to separately evaluate faculty member scholarship for each of the four forms and seek evidence of work representative of the different classifications of scholarship (Schweitzer, 2000; Tobin, Bordonaro, \& Schmidt, 2010). 
Research on PUIs in Canada revealed 70 percent of faculty members indicated the presence of some level of consideration of Boyer model elements in the faculty assessment process (Osakwe, Keavey, Uzok, Fedoruk, \& Osuii, 2015). However, Osakwe and colleagues also found that 60 percent of the faculty members participating in their study reported they were unaware of the Boyer model. Osakwe et al. (2015) further documented indications that the universities did not appear to have structures to increase faculty member awareness of the Boyer Model or support for gaining understanding of how to implement the model. (Osakwe, et al., 2015).

When faculty members embrace the Boyer model, there is commonly a direct impact on their students' educational experience (Ahern-Rindewll \& Quackenbush, 2015). An example of the impact on students' educational experiences was documented in the University of Portland's applied ethics-related research approach. The approach involves combining a team-taught ethics course designed to further student moral development with opportunities for student-faculty teams to pursue research on applied ethics in disciplines across the university. Ahern-Rindewll and Quackenbush found the approach led to positive student development outcomes including increased intellectual growth, cognitive development, critical thinking, and moral development. Ahern-Rindewll and Quackenbush also documented how a biology professor implementing the approach experienced changes in his relationship with students, particularly related to working through ethical questions as related to research. The team approach taken in the model implementation addressed the desire by many faculty members to gain support from and engage with colleagues to accomplish scholarship (Toth \& Sullivan, 2016).

Given the wide range of potential configurations for the implementation of the teacher-scholar model and the impact on both faculty member and student educational experience, there is warrant for exploring faculty members' perceptions of and ideas for implementing the model. Deeper understanding of faculty members' perceptions could inform plans for professional development and implementation to capitalize on the potential benefits of the model.

\subsection{Benefits and Support for the Teacher-Scholar Model}

Boyer's teacher-scholar model (1990) has the potential to improve the prospects of students, enrich the professional lives of faculty, and improve the quantity and quality of scholarship coming out of universities (Boyer, 1996). The potential benefits of the teacher-scholar model for undergraduate students are numerous (Prince, Felder, \& Brent, 2007). When faculty members engage in investigating ideas and producing knowledge, their students have the potential to learn about cutting-edge developments. Exposure to the results of cutting- edge research could potentially prepare students with deeper understanding of evidence-based knowledge generation, which would enable the students to be perceptive consumers of knowledge. As scholars, faculty members can invite students to participate in their scholarship, giving students the opportunity to exchange their status as passive learners to become active inquirers, collaborating on the process of learning and generating new knowledge (Boyer Commission, 1998). As Ryan and DePhillis (2010) point out, "the value of 
an original project rests on the supposition that it is more difficult to create knowledge than it is to learn something that is already accepted by people in the field.... then creating new knowledge has the potential to heighten [undergraduate] learning" (p. 2). Moreover, navigating research involves students in "[p]roblem-solving, teamwork, and co-operative learning," (Boyer Commission, 1998, pp. 15-16) skills that are arguably essential for students to learn as they prepare to be professionals.

Faculty members also benefit when asked to balance scholarship with teaching. Learning is a dynamic and on-going process. Thus, from the teaching-intensive perspective, Boyer's model gives faculty members a mechanism for engaging in scholarship which leads to their continued learning as well as providing a model for life-long learning for their students. For faculty members who might otherwise be immersed in their research, the model provides impetus for communicating their scholarship to students which completes the teacher and scholar process. By teaching students about their scholarship, faculty members can create the opportunity to consider a more expansive view of their research such as the related history, connections to the researcher's field and other fields, and potential applications. Furthermore, by including their students in their research to form a research team, faculty members enhance their potential to be exposed to new ideas and increase opportunities for scholarship. Alberts suggests that when we ask researchers to invest in teaching, we create an environment in "which the presence of students provides a 'lubrication" that breaks down intellectual barriers between faculty members" (Boyer Commission, 1998, p. 15). The mingling of students and faculty creates the conditions for productive "collisions of ideas" (Alberts qtd. in Boyer Commission 15).

From the perspective of those interested in the quality of the knowledge and information universities are producing, the Boyer model has the potential to help address some of the vulnerabilities of scholarship. Vexing questions have arisen recently around publication bias, the failure for researchers to reproduce desired results and the impact of the need to publish for promotion and tenure. The internal and external pressures on the scholarship of faculty members contribute to potential for fraud or the sharing of results that are rushed to press too hastily (Fanelli, 2009). By broadening the definition of scholarship, the Boyer model could provide support for quality research while diminishing the pressures on faculty members that motivate them to publish research results too quickly. The potential benefit of the Boyer model to the productivity of faculty members as scholars and teachers also provides justification for exploring faculty member knowledge of the teacher-scholar model.

\section{Method}

For our exploratory study we developed the following overarching research question; what is the knowledge, perceptions, preparation, and engagement in the teacher-scholar model by faculty members at a primarily teaching university? To answer our question we conducted an investigation of faculty members at a primarily undergraduate university using a survey to gather a combination of quantitative and qualitative data. To organize our investigation, we parsed our primary line of inquiry into the following guiding research questions:

- What are faculty members' knowledge of the teacher-scholar model? 
- What are faculty members' perceptions of the teacher-scholar model?

- How are faculty members engaging in the teacher-scholar model?

- Are there relationships between personal characteristics of the faculty members and their knowledge and perception of the teacher scholar model?

\subsection{Participants}

The participants in our research were faculty members working at a primarily undergraduate university located in the western United States who responded to our invitation to complete our survey. The university adopted an initiative for all faculty members to engage in the teacher-scholar model which included professional development offerings, workshops, and professional learning communities. The goal was to help increase the research productivity of the faculty members while remaining attentive to the teaching and learning focus of the institution. The institution was entering the second year of the initiative when we collected our data.

We had 179 connects to our online survey, 160 of those who clicked on our link progressed beyond the letter of information to begin the survey. We had 128 complete at least $95 \%$ of the selected response items. Respondents included 63 males, 61 females, and 4 that did not answer. The sample was composed of $57.5 \%$ of faculty members with doctorates and $32.3 \%$ holding masters degrees as their highest degree; the remaining participants held associates degrees $(1.6 \%)$, baccalaureate degrees $(4.7 \%)$, or professional degrees $(3.1 \%)$. About $65.6 \%$ of the faculty indicated they held terminal degrees. On average, the participants had worked for 13.9 years in higher education $(\mathrm{SD}=9.4)$. Respondents were distributed across the disciplines with $21 \%$ from arts and humanities, 14\% health and wellness, $29 \%$ from science, technology, engineering and mathematics (STEM), 19\% from professional program areas (e.g. education, business, criminal justice), 10\% from social sciences, and 7\% indicating "other." In response to the number of scholarly activities engaged in during the last three years, $17 \%$ indicated none, $40 \%$ indicated $1-3$, about $20 \%$ indicated $4-6,12.5 \%$ indicated $7-10$, and about $10.5 \%$ indicated 11 or more. Similarly, when asked how many scholarly works were contributed overall during their higher education career, about 50.5\% indicated $1-5,14 \%$ indicated 6-10, 9.5\% indicated $11-15$, about $7.5 \%$ indicated $16-20$, and about $18.5 \%$ indicated 21 or more contributed scholarly works.

\subsection{Survey of the Teacher-Scholar Model}

In our search of the literature, we were not able to find any extant instruments designed to assess faculty members' perceptions of, preparation for, and engagement in the teacher-scholar model. Therefore, we determined it was necessary to develop an instrument to gather the desired teacher-scholar data from the faculty members. We began our development with multiple discussions about the critical facets of the teacher-scholar model we should consider in relation to faculty members. The critical facets we identified were: knowledge of the teacher-scholar model, preparation to engage in the teacher-scholar model, engagement in the teacher-scholar model, and perceptions of the teacher scholar-model. 
Once we identified the facets of the teacher-scholar model we were interested in researching, we created four small groups from our team to develop a set of approximately 10 survey items in the context of one of the specific facets of interest, e.g. engagement in the teacher-scholar model. We compiled the items and then independently categorized the items in terms of the four facets of faculty members' perceptions, knowledge, and engagement with the teacher-scholar model. We continued to discuss the items until we either reached agreement or determined that the item was too ambiguous to categorize and therefore we removed it from consideration.

Once we categorized each of the items into our four facets, we created our survey. We then piloted the survey, with each group member completing the survey independently to determine whether there were any additional concerns with item alignment and to determine how much time it took to complete the survey. We made a few minor adjustments to our survey to increase readability and to further clarify the stems of the selected response items. Our final survey contained 25 selected response items and 3 free response items (see Table 1 for examples of items for each of the four facets we selected for our research).

Table 1. Example Items for our Four Facets of the Teacher-Scholar Model

\begin{tabular}{ll}
\multicolumn{1}{c}{ Facet of the Teacher- } \\
Scholar Model
\end{tabular}

In addition to our teacher-scholar model items, we also developed a small demographic survey. We limited the items in the demographic survey to keep the survey short, retain 
anonymity, and negate the participants' perception of identification through their responses to the demographic items.

\subsection{Data Collection}

We uploaded our survey to an on-line survey site and constructed the survey such that the first page of the survey was the Institutional Review Board (IRB)-approved letter of interest. An email invitation was sent to the faculty members at the institution. The email invitation contained a brief statement of the research goals and a link to the survey. We followed our initial invitation with a follow-up reminder four days later. We concluded our data collection after one week as we did not receive any additional responses after two days of sending our reminder.

\section{Results}

Prior to our analysis, we conditioned our data by reverse coding items that were negatively phrased and used the "replace missing data" feature in Statistical Package for the Social Sciences (SPSS) using the "replace with mean" option.

To assure consistency and interrater reliability in our coding of the qualitative data, we formed small teams to analyze each set of qualitative responses. Each teann met and reviewed the coding criteria and then each team member independently scored the same ten items and then compared their scores and coding results. The process took place multiple times until there was at least $80 \%$ agreement, and no codes were beyond a one-point difference. Once the interrater reliability was achieved the teams split up the remaining items and coded and scored them for further analysis. Details of the codes, results, and count are found in our reporting of the results.

\subsection{Knowledge of the Teacher-Scholar Model}

Our first research question asked, "What are faculty members' knowledge of the teacher-scholar model?" To answer this question we began by analyzing the qualitative responses to our free-response item asking the participants to share their definition of the teacher-scholar model. We coded the participants' definitions based on the extent to which the data reflected the critical elements of the teacher-scholar model (see Table 2).

We scored the responses based on the number of elements that the participants' conveyed in their definitions of the teacher-scholar model. If the response to the item was blank, we left the coding score blank as well. If no elements were present, then the score was " 0 ." We then added one point to the score for each additional element present in the definition. The range of possible scores was from " 0 " to " 4 " as we identified four essential elements that define the teacher-scholar model. The results of our codings along with example responses are in Table 3. 
Table 2. The Critical Elements of the Teacher-Scholar Model Used for Coding and Example Response

\begin{tabular}{ll}
\multicolumn{1}{c}{ General Coding Groups } & \multicolumn{1}{c}{ Example of Aligned Passage From Responses } \\
\hline $\begin{array}{l}\text { A convergence, or fusing of teaching and } \\
\text { scholarship (research) }\end{array}$ & $\begin{array}{l}\text { Teaching can be a scholarly activity if new } \\
\text { information is developed and shared with others in } \\
\text { one's profession. }\end{array}$ \\
$\begin{array}{l}\text { Multiple areas of scholarship (discovery, } \\
\text { integration, application, and teaching) are } \\
\text { acceptable }\end{array}$ & $\begin{array}{l}\text { Discovery, integration, research, application, } \\
\text { consideration across multiple disciplines }\end{array}$ \\
$\begin{array}{l}\text { Scholarship enhances teaching and teaching } \\
\text { enhances scholarship }\end{array}$ & $\begin{array}{l}\text { Bringing my own professional experiences and } \\
\text { progress into the classroom }\end{array}$ \\
$\begin{array}{l}\text { Scholarship is more than just research (discovery, } \\
\text { traditional research) }\end{array}$ & $\begin{array}{l}\text { Participate in scholarly activities that are in-line with } \\
\text { current best practices in their specific field }\end{array}$ \\
\hline
\end{tabular}

Table 3. Rankings, Count, Percent, and Example Reponses to the Coding of Definition of Teacher-Scholar Model

\begin{tabular}{|c|c|c|}
\hline Rankings & $\begin{array}{c}\text { Count } \\
(\%)\end{array}$ & Example Response \\
\hline 0 & $59(57 \%)$ & A teacher who is up to date in his/her field. \\
\hline 1 & $33(32 \%)$ & Faculty that are actively researching and applying their findings: \\
\hline 2 & $10(10 \%)$ & $\begin{array}{l}\text { The teacher scholar model embraces a view of education in which educators are } \\
\text { primarily concerned with teaching and expert pedagogy but actively engage in } \\
\text { scholarship that refines their understand of the field. }\end{array}$ \\
\hline 3 & $2(2 \%)$ & $\begin{array}{l}\text { Views the scholar as both a teacher and a researcher. Values research related not } \\
\text { only to a specialized content area but also pedagogical research tied to teaching } \\
\text { and learning. }\end{array}$ \\
\hline 4 & $0(0 \%)$ & N/A \\
\hline
\end{tabular}

We continued our analysis by creating a composite average score of our selected response items that were representative of knowledge of the teacher-scholar-model. We then compared the score to a value of " 3 " which is representative of moderate knowledge of the model. We found the average composite score to be $2.88(\mathrm{SD}=.47)$ which is significantly less than the middle value of " 3 " $(\mathrm{t}=2.82, \mathrm{p}=.006)$. Our finding suggests that the participants' perceived knowledge levels of the teacher-scholar model are less than a moderate level of knowledge. We did not find a difference in knowledge scores when using the coded score for the definition as a factor in an ANOVA $(\mathrm{p}=.17)$, which suggests that the perceived knowledge 
was about the same regardless of the quality of the definition of the teacher-scholar model.

\subsection{Perceptions of the Teacher Scholar Model}

Our second research question asked, "What are faculty members' perceptions of the teacher-scholar model?" To answer this question we began by analyzing the qualitative responses to our free-response item asking the participants to share their definition of scholarship. We coded the participants' definitions based on the extent to which the data reflected the critical elements of scholarship (see Table 3). The categories we developed for our coding are aligned with general perceptions of academic scholarship (for example see Glassick, Huber, \& Maeroff, 1997).

Table 3. Coding Considerations with an Example Response for Defining Scholarship

\begin{tabular}{ll}
\hline General Coding Groups & Example of Aligned Passage From Responses \\
\hline New knowledge/Advances understanding & New applications of existing knowledge \\
Work is made public & Publications, conference-presentations. \\
Systematic approach & Research based in the scientific method \\
Feedback on work - peer review & Any peer review journal \\
Consideration of prior knowledge & Challenges existing knowledge \\
Multiple approaches to the scholarship & Creative performances and patents \\
Collaboration with others & As well as research collaborations \\
\hline
\end{tabular}

Similar to how we scored the responses to our item asking the participants to define the teacher-scholar model, we scored the responses based on the number of elements that the participants' conveyed in their explanations of scholarship. If the response to the item was blank, we left the coding score blank as well. If no elements were present, then the score was " 0 ." We then added one point to the score for each additional element present in the definition. The range of possible scores was " 0 " to " 4 " as we identified four or more essential elements that frame scholarship. The results of our codings along with example responses are in Table 4.

We continued our analysis by creating a composite average score of our selected response items that were representative of perceptions of the teacher-scholar-model and perceived preparation to engage in scholarship $(\mathrm{N}=128)$. We maintain that perceptions of the teacher-scholar model and preparation to engage in scholarship are likely influenced by the way that faculty members define scholarship. We then compared the score to a value of " 3 " which is representative of moderate perceptions of the model. We found the average composite score for perception of the model to be $3.42(\mathrm{SD}=.68)$ which is significantly greater than the middle value of " 3 " $(\mathrm{t}=6.94, \mathrm{p}<.001)$, which suggests that the participants' 
perception levels of the teacher-scholar model are more positive than neutral. We did not find a significant difference for the average preparation score being at the moderate level $(\mathrm{M}=$ 3.13 , SD = .82), which suggests that participants perceived that they were moderately prepared to engage in scholarship. We also did not find a difference in scores for the perception of the model when using the coded score for defining scholarship as a factor in an ANOVA $(p=.61)$, or for perceptions of preparation to engage in scholarship $(p=.52)$. Our results suggest that the perceptions of the teacher-scholar model and perceived preparation was about the same regardless of definition of scholarship.

Table 4. Rankings, Count, Percent, and Example Reponses to the Coding of the Definition of Scholarship

\begin{tabular}{ccl}
\hline Rankings & Count (\%) & Example Response \\
\hline 0 & $22(19 \%)$ & Academic study or high-level learning \\
1 & $50(43 \%)$ & $\begin{array}{l}\text { Published in peer-reviewed fields of research. } \\
\text { Professional activity that includes discipline specific learning, } \\
\text { research and communication. } \\
\text { Beyond the classroom sharing of academic ideas and processes to the } \\
\text { public of interest whether the public be local professionals as in way of } \\
\text { consulting and collaborating (including presentation) or by way of } \\
\text { formal publication in academic periodical. }\end{array}$ \\
& $31(27 \%)$ & $\begin{array}{l}\text { Scholarship is the ability to analyze, investigate, synthesize, and } \\
\text { transfer knowledge between fields as well research and expand a } \\
\text { knowledge base and contribute to a body of information. }\end{array}$ \\
& $4(3 \%)$ &
\end{tabular}

\subsection{Engagement in the Teacher-Scholar Model}

Our third research question asked, "How are faculty members engaging in the teacher-scholar model?" To answer this question, we began by analyzing the qualitative responses to our free-response item asking the participants to share what should be accepted as scholarship. We maintain that faculty members' perceptions of what should be accepted as scholarship is associated with their engagement in the research. We coded the participants' definitions based on the extent to which the data reflected the critical elements of what should be accepted as scholarship (see Table 3).

Similar to how we scored the responses to our item asking the participants to define the teacher-scholar model, we scored the responses based on the number of elements that the participants conveyed in their explanations of what should be accepted as scholarship. If the response to the item was blank, we left the coding score blank as well. If no elements were 
present, then the score was " 0 ." We then added one point to the score for each additional element present in the definition. The range of possible scores was " 0 " to " 4 " as we identified four or more essential elements that frame what should be accepted as scholarship. The results of our codings along with example responses are in Table 5.

Table 5. Rankings, Count, Percent, and Example Reponses to the Coding of What Should Be Accepted as Scholarship

\begin{tabular}{|c|c|c|}
\hline Rankings & Count (\%) & Example Response \\
\hline 0 & $24(25 \%)$ & $\begin{array}{l}\text { Embracing content in your field and utilizing student feedback and } \\
\text { research to be effective }\end{array}$ \\
\hline 1 & $49(51 \%)$ & $\begin{array}{l}\text { Publications Presentations Supervision of student research Report } \\
\text { writing for various agencies Invited guest speaking }\end{array}$ \\
\hline 2 & $18(19 \%)$ & $\begin{array}{l}\text { Peer-reviewed publications; other professional publications such } \\
\text { as book reviews; professional papers at conferences. For } \\
\text { colleagues in the fine arts this could be shows, concerts, pieces of } \\
\text { music, films, etc. }\end{array}$ \\
\hline 3 & $4(4 \%)$ & $\begin{array}{l}\text { Reading other scholars' academic studies Publishing academic } \\
\text { studies Presenting academic studies Sharing other scholars' } \\
\text { findings in class discussions Sharing my scholarly findings in class } \\
\text { discussions }\end{array}$ \\
\hline 4 & $2(2 \%)$ & $\begin{array}{l}\text { Published articles in scholarly as well as practitioner publications; } \\
\text { conference presentations; grant writing; program evaluation report } \\
\text { writing; professional development presentations to others in the } \\
\text { field; peer review of journal submissions. }\end{array}$ \\
\hline
\end{tabular}

We continued our analysis by again comparing the average composite score for our items associated with resources and support for scholarship and with engagement in scholarship. We maintain that what is accepted as scholarship is likely to be associated with engagement in scholarship and the resources and support for scholarship. Again, we compared the average composite scores with the value of " 3 " which we considered to be representative of a moderate level of engagement and moderate level of perceived resources and support for scholarship. Our analysis revealed the engagement mean of 3.14 ( $\mathrm{SD}=.63$ ) to be significantly greater than moderate $(\mathrm{t}=2.45, \mathrm{p}<.016)$ which suggests a significant but slightly elevated level of engagement beyond moderate. For perceptions of support and resources for engaging in scholarship we found a mean of $2.73(\mathrm{SD}=.76)$ which suggests that perceptions of available support and resources to engage in scholarship was less than moderate. We did not find a relationship between quality of response to what should be accepted as scholarship and engagement $(\mathrm{p}=.24)$ and the perception of availability of resources and support for engaging in scholarship $(p=.87)$. 


\subsection{Relationships to Individual Characteristics}

Our fourth research question asked, "Are there relationships between personal characteristics of the faculty members and their knowledge and perception of the teacher-scholar model?" To answer this question we examined the items in our survey in relation to the faculty members' individual characteristics by conducting a bivariate correlational analysis (see Table 6).

Table 6. Correlations among Participant Personal Characteristics and Measures of Facets of Teacher-Scholar Model (TSM)

\begin{tabular}{|c|c|c|c|c|c|c|c|c|c|c|c|}
\hline & Degree & $\begin{array}{c}\text { Scholarly } \\
\text { works last } \\
3 \text { years }\end{array}$ & $\begin{array}{c}\text { Scholarly } \\
\text { works in } \\
\text { career }\end{array}$ & $\begin{array}{c}\text { Know } \\
\text { of } \\
\text { TSM }\end{array}$ & $\begin{array}{c}\text { Percept } \\
\text { of } \\
\text { TSM }\end{array}$ & $\begin{array}{c}\text { Engage } \\
\text { in } \\
\text { TSM }\end{array}$ & $\begin{array}{c}\text { Resources } \\
\& \\
\text { Support } \\
\text { for TSM }\end{array}$ & $\begin{array}{l}\text { Prep. for } \\
\text { TSM }\end{array}$ & $\begin{array}{c}\text { Accept as } \\
\text { Scholar-ship }\end{array}$ & $\begin{array}{l}\text { Define } \\
\text { TSM }\end{array}$ & $\begin{array}{c}\text { Define } \\
\text { Scholar-ship }\end{array}$ \\
\hline Years in HE & $.323^{* *}$ & $.318^{* *}$ & $.525^{* *}$ & $.196^{*}$ & .090 & $.316^{* *}$ & .115 & .175 & .141 & .052 & .166 \\
\hline Degree & & $.334^{* *}$ & $.401^{* *}$ & .074 & .143 & $.239^{* *}$ & .110 & .079 & $.206^{*}$ & .137 & $.393^{* *}$ \\
\hline $\begin{array}{l}\text { Scholarly } \\
\text { works last } 3 \\
\text { years }\end{array}$ & & & $.591^{* *}$ & $.266^{* *}$ & .090 & $.628^{* *}$ & .102 & $.327^{* *}$ & .184 & .055 & $.224^{*}$ \\
\hline $\begin{array}{l}\text { Scholarly } \\
\text { works in } \\
\text { career }\end{array}$ & & & & $.242^{* *}$ & .151 & $.466^{* *}$ & .110 & $.258^{* *}$ & $.274^{* *}$ & .100 & $.252^{* *}$ \\
\hline $\begin{array}{l}\text { Knowledge } \\
\text { of TSM }\end{array}$ & & & & & $.487^{* *}$ & $.414^{* *}$ & $.518^{* *}$ & $.485^{* *}$ & .054 & $.218^{*}$ & .147 \\
\hline $\begin{array}{l}\text { Perception } \\
\text { of TSM }\end{array}$ & & & & & & $.369^{* *}$ & $.472^{* *}$ & $.354^{* *}$ & .074 & $.291^{* *}$ & -.014 \\
\hline $\begin{array}{l}\text { Engagement } \\
\text { in TSM }\end{array}$ & & & & & & & $.266^{* *}$ & $.437^{* *}$ & .146 & .085 & .159 \\
\hline $\begin{array}{l}\text { Resources } \\
\& \text { Support } \\
\text { for TSM }\end{array}$ & & & & & & & & $.351^{* *}$ & -.011 & .050 & -.027 \\
\hline $\begin{array}{l}\text { Preparation } \\
\text { for TSM }\end{array}$ & & & & & & & & & $.252^{*}$ & $.197^{*}$ & .081 \\
\hline $\begin{array}{l}\text { Accept as } \\
\text { Scholarship }\end{array}$ & & & & & & & & & & $.289^{* *}$ & $.216^{*}$ \\
\hline Define TSM & & & & & & & & & & & .123 \\
\hline
\end{tabular}

$* \mathrm{p}<.05, * * \mathrm{p}<.01$

Our analysis revealed multiple positive relationships between personal characteristics and measures of various facets of scholarship and the teacher-scholar model. We found relationships between years in higher education and engagement in the teacher-scholar model and knowledge of the model. The highest degree obtained was found to be related to engagement in the teacher-scholar model and the quality of the responses to what is accepted as scholarship and definition of scholarship. The number of scholarly works in the last three years was related to engagement in the teacher-scholar model, knowledge of the model, preparation to engage in scholarship, and quality of the responses to providing a definition of scholarship. The number of scholarly works in faculty members' careers was found to be 
related to engagement in the teacher-scholar model, knowledge of the model, perception of the model, and the quality of the responses to what is accepted as scholarship and definition of scholarship.

\section{Discussion and Implications}

We set out to conduct a case study of a PUI to determine faculty members' knowledge, engagement, and perceptions of the teacher-scholar model at the institution because the model is being promoted to motivate higher levels of scholarly productivity. The adoption of the teacher-scholar model requires a change in culture with shifts from focus just on teaching, or just on research, to working toward achieving excellence in both activities to enhance effectiveness as university faculty members. Yet the scant empirical documentation regarding the adoption and implementation of the teacher scholar model motivated us to determine faculty members' knowledge, perceptions, preparation and engagement in the model.

For our first research question regarding knowledge of the model, we found that the faculty members were able to convey some aspects of the model, yet their knowledge was fragmented or incomplete. Some held misconceptions such as perceiving mentoring students involved in research as considered a teacher-scholar model-aligned activity. While mentoring is teaching, we maintain that when faculty members engage with their students as collaborators on research they are more likely to be in line with the expectations of the teacher-scholar model. Further, our finding of a less than moderate level of knowledge of the teacher-scholar model from our selected response items suggests that faculty members may not understand or fully comprehend the model. There are substantial implications for having constrained knowledge of the model and yet holding limited knowledge or misconceptions of the model. Determining effective ways to increase faculty members' knowledge and understanding of the teacher-scholar model may be a fruitful direction for future research and essential to the effective implementation and integration of the model.

Similar to the knowledge level of the teacher-scholar model, faculty members held limited knowledge and misconceptions regarding the definition of scholarship. We found very few responses that indicated that the faculty members held a comprehensive view of scholarship, as few could share more than just a couple of the elements that define scholarship. Several of the responses again referenced activities such as mentoring students as scholarly activities, which we maintain could be associated with the scholarship of teaching and learning given a structured research approach that includes a systematic collection of data to investigate some aspect of mentoring activities or outcomes. Our finding of positive perceptions of the teacher-scholar model suggests that the faculty members likely perceive that the model could lead to greater levels of scholarly activity. However, given the faculty members' limited knowledge and misconception of scholarship, their positive perceptions may be misaligned with what may actually be expected with producing scholarship in the teacher-scholar model. A potential direction for future research may include exploring how perceptions of the model may change with greater understanding of scholarship.

Our finding of a moderate level preparation to engage in scholarship suggests that faculty members may perceive themselves to be somewhat prepared to produce scholarly work. 


\section{Mll Macrothink}

International Research in Education

ISSN 2327-5499

2019, Vol. 7, No. 1

Considering the moderate level of perceived preparation to engage in scholarship in conjunction with the limited understanding of scholarship suggests that faculty members may need additional support and scaffolding to gain the confidence and knowledge needed to be productive scholars. A future direction for research may include examining how increasing preparation to engage in scholarship influences how faculty members define scholarship.

Our analysis of what the participants think should be accepted as scholarship was somewhat parallel to the way they defined scholarship, which is to be expected because of the similarity between the items. However, the differences in the responses and the consideration of teaching as scholarship suggests that while the faculty members can define scholarship as research-related activities, some indicated that teaching is an activity that should be considered scholarship. The misalignment between what should be accepted as scholarship and what is accepted as scholarship is likely reflective of a need for professional development and clarification of expectations. Interpreting the perceived engagement in scholarship showing slightly above moderate in the context of limited understanding of what should be accepted as scholarship suggests that while the faculty members perceive a slightly above-moderate level of engagement, the larger university community may not accept the activities they are engaged in as scholarship. Again, additional professional development may be fundamental to ensure engagement in scholarship that is aligned with activities and processes that are accepted as scholarship. Our finding that participants perceived moderate levels of support and resources may be associated with perception of productivity and scholarly engagement. A potential direction for future research includes an exploration of the resources and support faculty members perceive that they need to be productive scholars, and how providing the support and resources impacts their perceptions of what might be accepted as scholarship.

Our analysis of relationships among personal variables and knowledge, perception, and engagement in scholarship reveals a limited influence of years in higher education. Our finding suggests that faculty members may have entered their careers when the scholarly expectations were rather minor. However, over time the expectations have increased suggesting that productivity in the last three years and over the life span of their careers is likely a better indicator of knowledge, engagement, and perceptions of scholarship, which is what our data indicate. We also found that the level of the degree is a better indicator of knowledge, perception, and engagement in scholarship than years in education. We speculate that the expectations for engaging in scholarship in advanced degrees provides a greater level of preparation and exposure to scholarship. Working toward and earning an advanced degree influences how one perceives and thinks about scholarship. The association between degree level and knowledge, perception, and engagement in scholarship suggests that additional education, perhaps in the form of professional development, may increase faculty members' preparation and perception of scholarship that would then lead to greater levels of productivity.

\section{Limitations}

The first limitation of our research is our sample. Although we had over 100 participants in 
our research, they were drawn from the same institution, which we selected for a case study. The responses to our items are likely to vary with respect to the research intensity at the particular institution, the levels of professional development of the faculty at the institution, and the size of the institution. Exploring knowledge, perception, and engagement in the teacher-scholar model at different institutions is a useful and potentially firuitful direction for future research.

The second limitation is that the interpretation of the responses to our qualitative items was based on the text provided by the participants. It is possible that the participants may hold greater levels of knowledge and understanding than they conveyed in their responses, with time being the influence on the quality of the answers rather than knowledge. Exploring faculty members' knowledge through methods such as focus groups may be needed to provide additional insight regarding the understanding faculty members have of the teacher-scholar model.

\section{Conclusion}

One approach to engaging faculty members in activities that improve their scholarship and teaching is through the adoption and promotion of the teacher-scholar model. Yet few empirical studies have been conducted to determine the knowledge, perception, preparation, and engagement in the teacher-scholar model by faculty members. We attempted to address this gap in the literature through our exploratory investigation of a PUI as a case study. Through our research we determined that there is a need for additional professional development to support and promote the model with faculty members to effectively rely on the model to increase scholarly productivity along with teaching excellence.

\section{References}

Ahern-Rindell, A. \& Quackenbush, A. (2015). Applied ethics can foster the teacher-scholar model and impact undergraduate research campus-wide. Council on Undergraduate Research Quarterly, 36(1), 19-24.

Boyer Commission. (1998). Reinventing undergraduate education: A blueprint for America's research universities. Retrieved from https://dspace.sunyconnect.suny.edu/handle/1951/26012

Boyer, E. L. (1990). Scholarship reconsidered: Priorities of the professoriate. Princeton University Press: Lawrenceville, NJ.

Boyer, E. L. (1996). Clinical practice as scholarship. Holistic Nursing Practice, 10(3), 1-6. https://doi.org/10.1097/00004650-199604000-00003

Boyer, E. (2004). Chapter 2: Enlarging the perspective. Physical Therapy, 84(6), 571-575.

Brew, A. (2003). Teaching and research: New relationships and their implications for inquiry-based teaching and learning in higher education. Higher Education Research \& Development, 22(1), 3-18. https://doi.org/10.1080/0729436032000056571

Cruz, L., Ellern, J., Ford, G., Moss, H., \& White, B. J. (2009). Recognition and reward: SOTL and the tenure process at a regional comprehensive university. MountainRise, the 
International Journal of the Scholarship of Teaching and Learning, 5(3).

Fabricant, M., \& Brier, S. (2016). Austerity blues: Fighting for the soul of public higher education. Baltimore: Johns Hopkins University Press.

Fanelli, D. (2009). How many scientists fabricate and falsify research? A systematic review and meta-analysis of survey data. PLoS One, 4(5), e5738. https://doi.org/10.1371/journal. pone. 0005738

Gardner, J.C., McGowan, C.B., \& Moeller, S.E. (2010). Applying the teacher scholar model in the school of business. American Journal of Business Education, 3(6), 85-90. https://doi.org/10.19030/ajbe.v3i6.446

Glassick, C. E., Huber, M. T., \& Maeroff, G. I. (1997). Scholarship assessed: Evaluation of the professoriate. Special report. San Francisco, CA: Jossey Bass

Jencks, C. \& Reisman, D. (1968). The academic revolution. New York; Double Day.

Kenny, S. S., Thomas, E., Katkin, W., Lemming, M., Smith, P., Glaser, M., \& Gross, W. (2002). Reinventing undergraduate education: Three years after the Boyer Report. Stony Brook, NY: Boyer Commission on Educating Undergraduates in the Research University.

Kuh, G. D., Chen, D., \& Laird, T. F. N. (2007). Why Teacher-scholars matter: Some insights from FSSE and NSSE. Liberal Education, 93(4), 40-45.

Kuh, G.D., Kinzie, J., Schuh, J.H., \& Whitt, E.J. (2005). Never let it rest: Lessons about student success from high-performing colleges and universities. Change, 37(4), 44-51. https://doi.org/10.3200/CHNG.37.4.44-51

McKenna, J., Bickle, M, \& Carroll, J.B. (2002). Using scholarship to integrate teaching and research. Journal of Family and Consumer Sciences, 94(3), 39-45.

Osakwe, C., Keavey, K., Uzoka, F., Fedoruk, A., Osuji, J. (2015). The Relative importance of academic activities: autonomous values from the Canadian professoriate. Canadian Journal of Higher Education, 45(2), 1-22.

Prince, M. J., Felder, R. M., \& Brent, R. (2007). Does faculty research improve undergraduate teaching? An analysis of existing and potential synergies. Journal of Engineering Education, 96(4), 283-294. https://doi.org/10.1002/j.2168-9830.2007.tb00939.x

Ruscio, K. P. (2013). What does it meant to be a teacher-scholar? Peer Review, 15, 27-28.

Ryan, J.G. \& DePillis, L. (2010). Effective collaborations to support transformative research. Geology Faculty Publications. Retrieved from http://scholarcommons.usf.edu/gly_facpub/133

Schweitzer, L. (2000). Adoption and failure of the "Boyer Model" at the University of Louisville. Academic Medicine, 75(9), 925-929. https://doi.org/10.1097/00001888200009000-00015

Shulman, L.S. (1986). Paradigms and research programs in the study of teaching. Published in M. C. Wittrock (Ed.), Handbook of research on teaching (3rd ed., pp. 3-36). New York: 
Macmillian.

Tobin, D. J., Bordonaro, J. L., Schmidt, M. M., \& Hulse, D. (2010). Evidence of the Boyer model of scholarship in counselor education. Journal of Counselor Preparation and Supervision, 2(1), 2-9. https://doi.org/10.7729/21.0111

Toth, C. \& Sullivan, P. (2016). Toward local teacher-scholar communities of practice: Findings from a national TYCA survey. Teaching English in the Two Year College, 43(3), 247-273.

U.S. Department of Education. (2015). College scorecard data. Using federal data to measure and improve the performance of U.S. institutions of higher education. Retrieved from https://collegescorecard.ed.gov/assets/UsingFederalDataToMeasureAndImprovePerformance. pdf

White, S. R. (1999). Doctor of arts in secondary teacher education: Preparing the teacher-scholar. American Secondary Education, 28(2), 10-16.

Witt, P. L., Harris, K., Yarhouse, K., Sawyer, C. R., \& Behnke, R. R. (2007). Reconceptualizing the teacher-scholar model in university-level communication education. Human Communication, 10(4), 497-506.

Ziolkowski, E. J. (1996). Slouching toward scholardom: The endangered American college. College English, 58(5), 568-588. https://doi.org/10.2307/378757

\section{Copyright Disclaimer}

Copyright reserved by the authors.

This article is an open-access article distributed under the terms and conditions of the Creative Commons Attribution license (http://creativecommons.org/licenses/by/3.0/). 